\title{
BMJ Global Health Economic valuation of the impact of a large surgical charity using the value of lost welfare approach
}

\author{
Daniel Scott Corlew, ${ }^{1}$ Blake C Alkire, ${ }^{2,3,4}$ Dan Poenaru, ${ }^{5,6}$ John G Meara, ${ }^{7}$ \\ Mark G Shrime 8,9
}

To cite: Corlew DS, Alkire BC, Poenaru D, et al. Economic valuation of the impact of a large surgical charity using the value of lost welfare approach. BMJ Global Health 2016;1:e000059. doi:10.1136/bmjgh-2016000059

- Additional material is available. To view please visit the journal (http://dx.doi.org/ 10.1136/bmjgh-2016000059).

Received 11 April 2016 Revised 4 October 2016 Accepted 11 October 2016

CrossMark

For numbered affiliations see end of article.

\section{Correspondence to} Dr Daniel Scott Corlew; Dscorlew@gmail.com

\section{ABSTRACT}

Background: The assessment of the economic burden of surgical disease is integral to determining allocation of resources for health globally. We estimate the economic gain realised over an 11-year period resulting from a vertical surgical programme addressing cleft lip (CL) and cleft palate (CP). Methods: The database from a large nongovernmental organisation (Smile Train) over an 11-year period was analysed. Incidence-based disability-adjusted life years (DALYs) averted through the programme were calculated, discounted $3 \%$, using disability weights from the Global Burden of Disease (GBD) study and an effectiveness factor for each surgical intervention. The effectiveness factor allowed for the lack of $100 \%$ resolution of the disability from the operation. We used the value of lost welfare approach, based on the concept of the value of a statistical life (VSL), to assess the economic gain associated with each operation. Using income elasticities (IEs) tailored to the income level of each country, a country-specific VSL was calculated and the VSL-year (VSLY) was determined. The VSLY is the economic value of a DALY, and the DALYs averted were converted to economic gain per patient and aggregated to give a total value and an average per patient. Sensitivity analyses were performed based on the variations of IE applied for each country.

Results: Each CL operation averted 2.2 DALYs on average and each CP operation 3.3. Total averted DALYs were 1325678 (CP 686577 and CL 639 102). The economic benefit from the programme was between US\$7.9 and US\$20.7 billion. Per patient, the average benefit was between US\$16 133 and US $\$ 42351$. Expense per DALY averted was estimated to be $\$ 149$.

Conclusions: Addressing basic surgical needs in developing countries provides a massive economic boost through improved health. Expansion of surgical capacity in the developing world is of significant economic and health value and should be a priority in global health efforts.

\section{INTRODUCTION}

The Lancet Commission on Global Surgery (LCoGS) highlighted the need for surgical

\section{Key questions}

What is already known about this topic?

- Previous efforts to assess the economic value to society of surgical services in the developing world have used the human capital approach as well as the more holistic value of a statistical life approach but have been quite limited and have used extensive modelling of the surgical services.

\section{What are the new findings?}

- The value of lost welfare and value of a statistical life approaches are robust methodologies to attempt to capture the economic value of health interventions.

- Using robust methodology, on average each cleft lip and cleft palate repair was found to contribute to economic well-being at the individual level (US\$16.1-US\$42.3K) and at the aggregate level (US\$7.9-US\$20.7 billion over 11 years). It is speculated that the expense of the programme per disability-adjusted life year averted was US $\$ 149$.

\section{Recommendations for policy}

- This study indicates that the expansion of surgical capacity in the developing world is of significant economic and health value and should be a priority in global health efforts.

services in the developing world. ${ }^{1}{ }^{2}$ Previous studies have addressed that need ${ }^{3}{ }^{4}$ and the economic impact of surgical diseases. ${ }^{5-10}$ These studies have examined either the economic loss due to failure to meet surgical needs, or the potential economic gain when the need is incompletely addressed. The losses to society and to individuals because of lack of surgical care are immense; 4.8 billion people, over half of the global population, lack access to such care. ${ }^{11}$ For those with access to care, 81 million people a year face catastrophic expenditure (defined as $10 \%$ of household or $40 \%$ of non-food expenditure) because of surgical conditions, with the 
preponderance of these costs being non-medical. ${ }^{12}$ Analyses require defining the health problem, the intervention and the counterfactual in addition to modelling the relationship between health and macroeconomic outcomes. ${ }^{13}$ This can be challenging and controversial. Cost-of-illness (COI) studies, which combine direct and indirect (ie, lost productivity) cost of a disease, are most prominent. Within COI studies, the valuation of lost productivity based on gross national income (GNI) or gross domestic product (GDP), termed the 'human capital approach', is prevalent. This method emphasises macroeconomic losses associated with poor health and consequent treatment and has been criticised due to the unclear economic meaning that results from applying per capita measures of economic output to lost health and productivity. This criticism results in part from the fact that GNI and GDP are not aggregate measures of individual economic productivity, and also there is typically no accounting for unemployment. ${ }^{14}$

The value of a statistical life (VSL), an economic concept that has been refined over the past half century, attempts to define a monetary value for changes in health risks. VSL estimates are derived by assessing how individuals value trade-offs between wealth and small changes in their mortality risk. VSL studies can be either survey-based, so-called 'stated preference' studies, or use a 'revealed preference' approach, relying on wage differentials of occupations with varying risk profiles. ${ }^{15}$ This paper applies the value of lost welfare (VLW) approach to the work of a large non-governmental organisation (NGO) over an 11-year period, adopting the concept of VSL. It is intended to capture the total economic welfare (market and non-market) losses associated with disability or premature mortality, including the loss of utility due to lost leisure time and foregone consumption opportunities, along with less tangible losses such as those due to pain and suffering.

Smile Train (ST) is an international charity that in addition to training and resources provides financial support on a case-by-case basis to hospitals and surgeons in access-limited regions for the repair of cleft lip (CL) and cleft palate (CP). This programme has been previously evaluated in terms of averted burden of disease $(\mathrm{BoD})^{16}$ and the 'human capital' approach described above. ${ }^{17}$ The current study uses the economic valuation methodology applied by the LCoGS to value this vertically oriented surgical intervention.

\section{METHODS}

This study determined the clinical effect of the cleft surgery programme by first estimating the total disability-adjusted life years (DALYs) averted through the operative interventions, then determined the macroeconomic benefit of that work. Determining the counterfactual was challenging in that it is impossible to know how many of the patients would have been cared for in the absence of the programme. An attempt was made to identify what that proportion of our total may have been, based on anecdotal information from a time prior to the existence of ST. This endeavour, as could be expected, lacked quantitative rigour, and the findings were consistent with the authors' own guesses of a maximum of about $10 \%$ of the cases carried out in this study. In developing countries, the relative lack of financial incentives without the programme contrasted with the $100 \%$ rate of reimbursement with it could be reasonably invoked as accounting for this change. We conducted the study first comparing health and economic benefits to a postulated counterfactual of no intervention, then calculated those benefits on the basis of only $90 \%$ of the patients receiving care because of the programme.

The ST global database for 2001-2011 provides the following anonymised data: age at operation, country and surgical intervention (CL or CP repair). This was the same database used for a previous study that applied a human capital approach to estimate economic benefit. ${ }^{17}$ Country-specific and age-specific life expectancy estimates were obtained from the UN and WHO tables ${ }^{18}$ and GNI per capita values were taken from the World Bank data. We adjusted these GNI/capita figures for inflation to 2011 international dollars, prior to our making the calculations for the study. Economic benefit was calculated using the Purchasing Power Parity figures in order to avoid the variables of relative price differences between countries, and expressed in 2011 international dollars. ${ }^{19}$

Disability weights (DWs) for the untreated conditions of CL and CP were extracted from the Global Burden of Disease (GBD) study. ${ }^{20}$ DALYs secondary to a disease are calculated by adding years of life lost (YLLs) and years lost to disability (YLDs). Given that we did not account for potential mortality, only YLDs were calculated for this study. We adopted an incidence perspective when calculating YLDs; consequently, we discounted their future value over the patient's remaining life at $3 \%$. Residual postoperative DALYs were estimated by the method of McCord and Chowdhury ${ }^{21}$ and used by others $^{22-24}$ in which allowance is made for failure of the intervention to resolve $100 \%$ of the disability. This method introduces a risk of permanent disability (RPD) if there is no intervention and an estimate of residual disability (ERD) following the intervention. For cleft deformities, the RPD is 1.0 , as all individuals with these deformities will continue to suffer disability in the absence of intervention. We used an ERD of 0.8 for CL repair and 0.5 for $\mathrm{CP}$ repair, postulating that a CL repair roughly resolves $80 \%$ of the disability and a $\mathrm{CP}$ repair $50 \%$. The averted DALYs were calculated by multiplying the age-specific, year-specific and country-specific years left to live at the age of operation by the DW and ERD for each patient.

We estimated the VSL and its annualised equivalent, the VSL-year (VSLY), for each country as described by Alkire $e t a l .{ }^{10}$ The VSLY is taken to be the value of a 
DALY, and therefore our assessment of benefit multiplies total YLDs averted by ST interventions by the VSLY specific to the patient's country, age and year of operation.

The mathematical details of the derivation of the conversion of DALYs into country-specific VSLY are shown in the online supplementary material.

\section{RESULTS}

A total of 548233 patients from 84 countries were included in the database. In total, 4113 patients were excluded from the economic analysis because of lack of GNI per capita data in the World Bank tables. These exclusions came from 14 countries, with 1039 of these excluded patients coming from Argentina. Another 865 cases from five countries were excluded because of lack of income grouping data. With the exception of 377 patients from the Palestinian Territories, for which life table data were not available, these patients were included in the calculation of averted DALYs. The gender distribution was $62 \%$ male and $38 \%$ female. The median age at the time of operation was 2; the average was $6.07( \pm 8.14 \mathrm{SD})$ years; for CL this was 5.55 and for CP 6.78 years.

Each CL intervention averted 2.2 DALYs on average and each CP intervention 3.3. With 3\% discounting and assuming that only $90 \%$ of the patients in the study would have been unique beneficiaries of the programme, the total averted DALYs were 1325678 (CP 686577 and CL 639 102). These data are presented in table 1 .
The economic benefit derived from these procedures was between US\$7.9 and US $\$ 20.7$ billion. Per patient, the average benefit was between US\$16 133 and US $\$ 42351$.

The economic benefit varied with the income elasticity (IE) postulated. We first selected an IE of 0.55 for upper middle-income countries (UMICs; ascertained as reasonable for this income level), ${ }^{25}$ and an IE of 1.0 for low income and lower middle-income countries (LMICs) and low-income countries (LICs; consistent with evidence that lower income populations exhibit a higher elasticity for VSL). ${ }^{26}$ Using these elasticities, there was a high estimate for total economic gain of US\$20.7 billion, with an average of US\$36 897 per LIC/LMIC patient and US \$173 347 per UMIC patient. The total for LICs and LMICs was US $\$ 17.3$ billion and that for UMICs was US $\$ 3.4$ billion. These data, including the stratification of CL repair and CP repair, are presented in table 2.

We then selected a more conservative IE of 1.0 for UMICs and 1.5 for LMICs and LICs. With these elasticities, the total economic gain was the low end estimate of US $\$ 7.9$ billion, with an average of US $\$ 12711$ per LIC/ LMIC patient and US\$98 329 per UMIC patient. The total for LICs and LMICs was US $\$ 5.97$ billion, and that for UMICs was US $\$ 1.92$ billion. These data are presented in table 3 .

Owing to the incidence perspective associated with the DALYs calculated, we did not perform economic analysis of non-discounted DALYs. However, averted DALYs calculated without discounting, and again assuming that only $90 \%$ of these patients were true

Table 1 DALYs averted, total and per patient

\begin{tabular}{lllllll}
\hline & $\begin{array}{l}\text { Average of age } \\
\text { at treatment } \\
\text { (rounded) }\end{array}$ & $\begin{array}{l}\text { Surgically } \\
\text { avertable disability } \\
\text { (DALYs) no } \\
\text { discount }\end{array}$ & $\begin{array}{l}\text { Surgically } \\
\text { avertable disability } \\
\text { (DALYs) 3\% } \\
\text { discount }\end{array}$ & $\begin{array}{l}\text { Number of } \\
\text { patients }\end{array}$ & $\begin{array}{l}\text { Average averted } \\
\text { DALYs per } \\
\text { patient no } \\
\text { discount }\end{array}$ & $\begin{array}{l}\text { Average averted } \\
\text { DALYs per } \\
\text { patient 3\% } \\
\text { discount }\end{array}$ \\
\hline $\begin{array}{l}\text { Cleft } \\
\text { palate }\end{array}$ & 6.78 & 1596501 & 686577 & 207006 & 7.71 & 3.32 \\
$\begin{array}{l}\text { Cleft } \\
\text { lip }\end{array}$ & 5.55 & 1474927 & 639102 & 286064 & 5.16 & 2.23 \\
\hline Total & 6.07 & 3071427 & 1325678 & 493070 & 6.23 & 2.69 \\
\hline
\end{tabular}

DALY,disability-adjusted life year.

Table 2 Economic benefit setting IEs at 1.0/0.55 (upper bound)

\begin{tabular}{|c|c|c|c|c|c|c|c|c|}
\hline & $\begin{array}{l}\text { Number } \\
\text { of LIC } \\
\text { and } \\
\text { LMIC } \\
\text { patients }\end{array}$ & $\begin{array}{l}\text { Number } \\
\text { of UMIC } \\
\text { patients }\end{array}$ & $\begin{array}{l}\text { Economic } \\
\text { benefit LIC and } \\
\text { LMIC IE }=1.0\end{array}$ & $\begin{array}{l}\text { Economic } \\
\text { benefit UMIC } \\
\text { IE }=0.55\end{array}$ & $\begin{array}{l}\text { Total economic } \\
\text { gain (LIC, } \\
\text { LMIC, UMIC) IE } \\
1.0 / 0.55\end{array}$ & $\begin{array}{l}\text { Average } \\
\text { economic } \\
\text { gain per } \\
\text { patient LIC } \\
\text { and LMIC } \\
\text { IE=1.0 }\end{array}$ & $\begin{array}{l}\text { Average } \\
\text { economic } \\
\text { gain per } \\
\text { patient } \\
\text { UMIC } \\
\text { IE=0.55 }\end{array}$ & $\begin{array}{l}\text { Average } \\
\text { economic } \\
\text { gain per } \\
\text { patient IE } \\
1.0 / 0.55\end{array}$ \\
\hline $\begin{array}{l}\text { Cleft } \\
\text { palate }\end{array}$ & 196283 & 9265 & 9395345138 & 1950757462 & 11346102600 & 47866 & 210560 & 55199 \\
\hline $\begin{array}{l}\text { Cleft } \\
\text { lip }\end{array}$ & 273086 & 10275 & 7923094387 & 1436428296 & 9359522683 & 29013 & 139794 & 33030 \\
\hline Total & 469369 & 19540 & 17318439525 & З 387185759 & 20705625284 & 36897 & 173347 & 42351 \\
\hline
\end{tabular}

IE, income elasticity; LIC, low-income country; LMIC, lower income and middle-income country; UMIC, upper income and middle-income country. 
Table 3 Economic benefit setting IE at 1.5/1.0 (lower bound)

\begin{tabular}{|c|c|c|c|c|c|c|c|c|}
\hline & $\begin{array}{l}\text { Number } \\
\text { of LIC } \\
\text { and } \\
\text { LMIC } \\
\text { patients }\end{array}$ & $\begin{array}{l}\text { Number } \\
\text { of UMIC } \\
\text { patients }\end{array}$ & $\begin{array}{l}\text { Economic } \\
\text { benefit LIC } \\
\text { and LMIC } \\
\text { IE=1.5 }\end{array}$ & $\begin{array}{l}\text { Economic } \\
\text { benefit UMIC } \\
\text { IE }=1.0\end{array}$ & $\begin{array}{l}\text { Total } \\
\text { economic gain } \\
\text { (LIC, LMIC, } \\
\text { UMIC) IE 1.5/ } \\
1.0\end{array}$ & $\begin{array}{l}\text { Average } \\
\text { economic } \\
\text { gain per } \\
\text { patient LIC } \\
\text { and LMIC } \\
\text { IE=1.5 }\end{array}$ & $\begin{array}{l}\text { Average } \\
\text { economic } \\
\text { gain per } \\
\text { patient } \\
\text { UMIC } \\
\text { IE=1.0 }\end{array}$ & $\begin{array}{l}\text { Average } \\
\text { economic } \\
\text { gain per } \\
\text { patient IE } \\
1.5 / 1.0\end{array}$ \\
\hline $\begin{array}{l}\text { Cleft } \\
\text { palate }\end{array}$ & 196283 & 9265 & 3303594721 & 1111203556 & 4414798277 & 16831 & 119941 & 21478 \\
\hline Total & 469369 & 19540 & 5966041512 & 1921342009 & 7887383521 & 12711 & 98329 & 16133 \\
\hline
\end{tabular}

IE, income elasticity; LIC, low-income country; LMIC, lower income and middle-income country; UMIC, upper income and middle-income country.

beneficiaries of the programme, totalled 3071427 (CP 1596 501, CL 1474 927) and for each patient, each CL intervention averted an average of 4.8 DALYs and each CP intervention 7.3.

The averted BoD data stratified by country are presented in table 4 .

\section{DISCUSSION}

Using the economic concept of the VSL to convert clinical benefit to economic gain, we found a total benefit from a surgical programme in developing countries that addressed CL and palate over an 11-year period to be at least US $\$ 7.9$ billion, up to US $\$ 20.7$ billion. For CL, this was an average of between US\$12 255 and US\$33030 per patient over their lifetimes; for $\mathrm{CP}$, it ranged between US\$21 478 and US\$55 199. Our per capita estimates are lower than other studies that have used VSL methodology (table 5).

The human capital approach generally yields lower estimates, ${ }^{6} 827$ though the previous evaluation of the current data using that approach found a higher upper bound when calculating with no discounting or age weighting and using the DWs from the GBD study rather than an effectiveness factor for the calculation of DALYs with the intervention. ${ }^{17}$ This study makes an effort to apply the most appropriate IE-VSL estimate supported by the literature to each country, which yields lower VSL estimates for LMICs, which comprised the majority of the patients. Alkire et at did not use countryspecific IE-VSLs, which resulted in a uniformly higher VSL estimate than is seen in this study. Hughes et $a l^{27}$ did so, but that study involved only one country (Ecuador). The Corlew study also involved only one country (Nepal) and used a VSL from Indian research for the VSL. ${ }^{8}$

This study uses a quite conservative effectiveness factor to attempt to avoid overestimating the value of the interventions. It is quite possible that this factor could in reality be significantly higher, especially in higher income countries. It is possible that as the per capita income increases, factors such as nutrition, dental care and oral hygiene, hospital conditions, available follow-up care, ancillary services such as speech, orthodontic care, etc, might more commonly accompany the operative repair, all resulting in an ultimate outcome much better than ascribed through Effectiveness Factors (EFs) of 0.5 for $\mathrm{CP}$ and 0.8 for CL.

More conservative estimates of the EF would be considered unlikely, but nevertheless can be examined from the perspective of sensitivity analysis for this study. This is addressed below.

When the data from this study are stratified into LMIC and UMIC, the differences between this study and the others are diminished for the UMIC countries and slightly accentuated for the LMICs (table 6).

We postulate that our more specific application of IE data, coupled with our appropriate use of discounting of the incidence-based DALYs calculated, yields a closer approximation of economic benefit than previous methods.

As part of the LCoGS work, Alkire et al examined the global macroeconomic impact of the surgical BoD using two economic approaches. These approaches, the value of lost output (VLO) and VLW, attempt to estimate the macroeconomic consequences of disease from different perspectives, but only the latter encompasses the total value of economic welfare losses. ${ }^{10}$

The VLO approach uses the WHO EPIC model, ${ }^{28} 29$ which models how mortality due to a particular disease process affects the labour force and capital stock of a country, thereby affecting its GDP. In this study, mortality is not considered; rather, how society values the loss of health, measured in DALYs, is the metric of interest. There are no data currently available regarding the correlation between CL/CP and participation in the labour force. While a correlation between CL/CP and participation in the labour force is intuitive, and the implication of this paper and others ${ }^{6} 827$ is that such is true, it is unknown what that relationship is. Therefore, attempting to fit the VLO model to the current data was deemed to be of insufficient reliability and was not done.

The VLW approach, however, is more appropriate for assessing the total value of the economic gain provided by this vertical programme. By comparison, the human capital approach described above is quite feasible, yet 
Table 4 Averted burden of disease by country

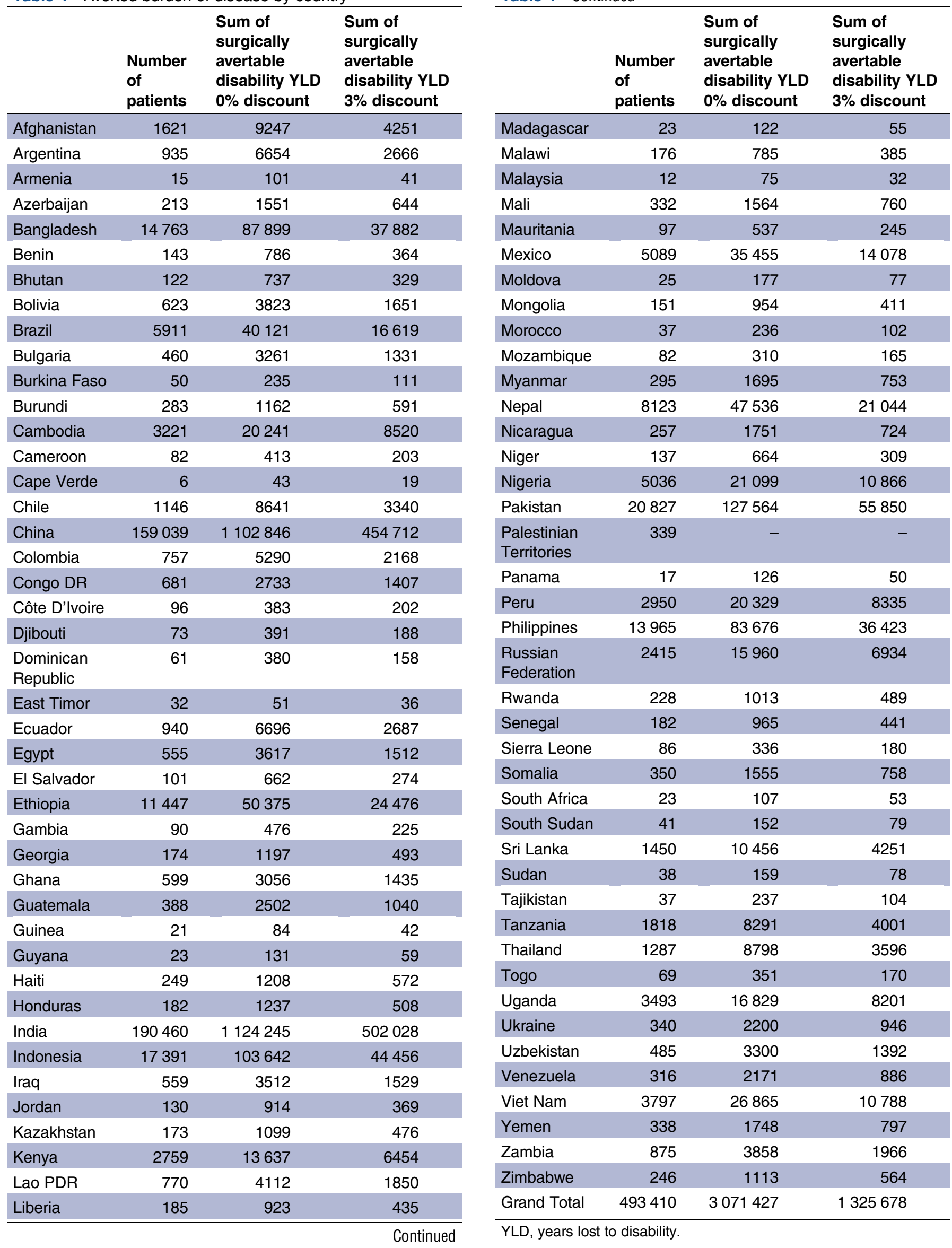


Table 5 Comparison of economic estimates of cleft lip and palate care using VSL

\begin{tabular}{lrrrrr}
\hline & \multicolumn{3}{c}{ Cleft lip } & & \multicolumn{2}{c}{ Cleft palate } \\
\cline { 2 - 3 } & Lower & Upper & & Lower & Upper \\
\hline Aggregate (current) & 12255 & 33030 & 21478 & 55199 \\
\hline Nepal (current) & 2094 & 10904 & 3113 & 16062 \\
\hline Corlew 2009 Nepal & 56919 & 143363 & 152372 & 375412 \\
\hline SSA (current) & 2874 & 12535 & 5058 & 20799 \\
Alkire 2011 SSA & 89016 & 160361 & 341586 & 614849 \\
\hline Ecuador (current) & 21721 & 51514 & 31559 & 74932 \\
Hughes 2012 Ecuador & 52967 & 141736 & 145803 & 390153 \\
\hline
\end{tabular}

VSL, value of a statistical life. SSA, sub-Saharan Africa

does not account for all the potential losses associated with CL/CP, suffers from an unclear economic meaning given that unemployment is rarely accounted for, and per capita measures of economic output (GDP per capita, GNI per capita) do not claim to be one-to-one estimates of aggregate individual economic productivity.

The number of DALYs averted, over 1.3 million when discounted at $3 \%$, is indicative of real and sustained value in the health of the populations affected by this surgical programme. The total for CL and CP each is similar, despite the greater number of CLs in the study. This probably reflects a number of factors: parents may not bring the children with CP in for care, some of the surgeons may not repair palates or may be limited in their capacity to do so, and there may be an unknown mortality of patients with palate precluding their presentation for care. ${ }^{30}$

The median age of 2 indicates that most patients are receiving care at close to the optimal age; the much higher average of 6.07 is skewed by the number of patients presenting in adulthood, much older than would allow them a more ideal benefit from repair. It is reasonable to speculate that many of these adult patients were denied schooling on par with their counterparts, and consequently their economic benefit, even from their age of repair, may be less than that gained by people treated in infancy.

The economic benefit realised is expectedly substantial, given that this study examines a programme that can provide lifetime resolution of a significant defect. While it would be optimal for these patients to receive further episodic care in order to improve their results further, there is no need for ongoing or maintenance care in order to continue the benefits conferred by the original operation. It is completely intuitive that returning these patients to the possibility of gainful employment and removing the need for caregiving that can be associated with these deformities could provide a major economic boost to society.

Given the relationship between income and VSL, it is expected that per capita UMIC benefit would be substantially greater than that seen in LMICs. On a per patient basis, this is indeed true (table 2). The sum, though, reflects the markedly greater work carried out in LMICs during the years of this study. ST is designed and intended to increase access to surgical care where it is lacking, which is largely in LMICs.

The cost of this programme overall was about US $\$ 197$ million (Personal communication with Mackinnon Engen, Smile Train, 2015). While it is impossible to speculate how many of these patients might have been cared for in the absence of the programme, our estimate of $10 \%$ is quite reasonable. The true counterfactual is unknown, so a 'return on investment' (ROI) of between 40 and 105 dollars per dollar spent, as well as a cost benefit ratio of US $\$ 149$ per DALY averted, is only speculation.

The problem of poor access to surgical care is arguably one of the greatest issues facing the global health community. ${ }^{1}$ This study indicates that the value of a vertical programme providing surgical care for one disease, orofacial clefting, can be substantial. Such a programme does not, however, delve into the complex task of strengthening health systems and infrastructure development that is necessary to improve surgical care. Infrastructure, training surgeons, anaesthesia providers, nurses and others integral to the provision of surgical care, governmental and NGO commitment and support, and cultural acceptance are all necessary for the scaling of benefits seen in this study. There will undoubtedly continue to be the yin and yang of more thorough addressing of smaller pieces of the surgical pie as seen here as opposed to addressing of the greater surgical need.

\section{Limitations}

Mortality due to cleft lip and palate (CLP) was not considered in this study, despite the presence of a small but unknown mortality risk associated with CP. Christensen and colleagues found increased mortality (mortality ratio 1.4 for males and 1.8 for females) in patients with

Table 6 Comparison of LMIC, UMIC and combined economic estimates (US\$)

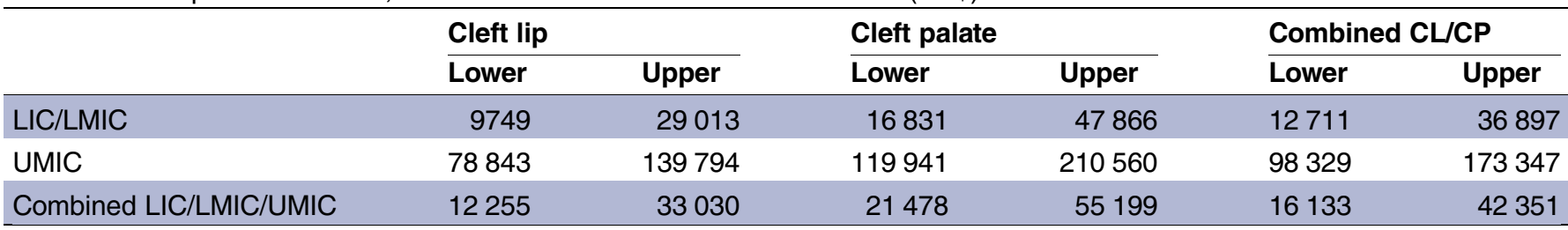

CL, cleft lip; CP, cleft palate; LIC, low-income country; LMIC, lower income and middle-income country; UMIC, upper income and middle-income country. 
CLP up to age 55, with the increase essentially exclusively due to patients with CLP as opposed to CL alone. They also found that this increased risk was equivalent over the time intervals of age $0-1,2-17$ and $18-55$. This was multifactorial, although suicide was a significant factor. $^{31}$ Carlson and colleagues, in a literature meta-analysis found an increase in mortality through the first year of life. This was substantially greater for people with associated anomalies (OR 9.47) than for isolated CLP (OR 2.07). ${ }^{32}$ Both of these studies addressed only patients from high-income countries, and it is quite reasonable to consider that mortality might be higher in the developing country population largely addressed in this study. Dai $e t a l^{33}$ reported a neonatal mortality of over $6 \%$ in patients with $\mathrm{CL} \pm \mathrm{CP}$ without associated anomalies in a developing country setting, consistent with this supposition. In a similar setting, Wilson and Hodges extrapolated that as many as $91 \%$ of patients with CP may die prior to reasonable presentation for repair. ${ }^{30}$

It is apparent that any consideration of mortality (YLLs in addition to YLDs in the calculation of DALYs) would increase the calculated value of the interventions in this study.

By necessity, this study has invoked a number of assumptions, starting with those of the GBD study in the development of DWs. The DWs from the 2004 study were revised from those of the original study and included CIs, but for CP and CL included only a single, composite DW including all people with a cleft, including those who had been treated. ${ }^{34}$ Since this study specifically addresses only people who had had no treatment, these values were not appropriate for this study. The original GBD study published treated and untreated DWs, which were used in the current work. By postulating that an appropriate level of uncertainty for these DWs was an SD of 0.25 of the value, calculated as ( (value) $\pm 1.96 \times 0.25$ (value)), we could determine an estimate of the uncertainty associated with this aspect of our estimates. These calculations are summarised in table 7. They indicate that with the lower end of the DW value, the programme contributed between $\$ 3.7$ and $\$ 10.0$ billion to the economy, depending on the IEs considered. At that lower bound of the DWs, the speculated cost per DALY averted was \$291, and the ROI was between 19 and 51. At the higher end, these numbers were US $\$ 11.8-\mathrm{US} \$ 30.8$ billion, the cost per DALY averted $\$ 100$, and the ROI between 60 and 157 .

Values to reflect the effectiveness of the intervention (surgical repair of the cleft), here set conservatively at 0.8 and 0.5 for CL and CP, respectively, are also purely assumptions. There are no data actually quantifying what constitutes optimal rehabilitation of patients with CLP, and it would be quite difficult to apply such a determination across economic and cultural divides. Analysis of various scenarios using lower and higher EFs was performed and is summarised in table 8. A higher EF may well be more appropriate, and of course indicates even greater value to the programme. Lower ones might be argued, and while they indicate decreasing values of the programme, even at EFs of 0.2 and 0.5 (only 20\% efficacy of the surgical repair of a CP and $50 \%$ for repair of CL), there is still significant value of

Table 7 Sensitivity analysis of DWs

\begin{tabular}{|c|c|c|c|c|c|c|}
\hline & $\begin{array}{l}\text { Total economic } \\
\text { gain IE } 1.5 / 1.0\end{array}$ & $\begin{array}{l}\text { Total economic } \\
\text { gain IE 1.0/0.55 }\end{array}$ & $\begin{array}{l}\text { Sum of DALYs } \\
\text { averted } 3 \% \\
\text { discount }\end{array}$ & $\begin{array}{l}\text { \$/DALY } \\
\text { averted }\end{array}$ & $\begin{array}{l}\text { ROI IE } \\
1.5 / 1.0\end{array}$ & $\begin{array}{l}\text { ROI IE } \\
1.0 / 0.55\end{array}$ \\
\hline $\begin{array}{l}\text { DW lower bound } \\
\text { (CP } 0.118, \mathrm{CL} \\
0.050)\end{array}$ & 3744122425 & 10081309630 & 676791 & 291 & 19 & 51 \\
\hline $\begin{array}{l}\text { DW (CP 0.231, CL } \\
0.098)\end{array}$ & 7887383521 & 20705625284 & 1325678 & 149 & 40 & 105 \\
\hline
\end{tabular}

CL, cleft lip; CP, cleft palate; DALY, disability-adjusted life year; DW, disability weight; IE, income elasticity; ROI, return on investment.

Table 8 Scenario analysis of effectiveness factor

\begin{tabular}{|c|c|c|c|c|c|c|}
\hline & \multirow{2}{*}{$\begin{array}{l}\text { Total economic gain } \\
\text { IE } 1.5 / 1.0\end{array}$} & \multirow{2}{*}{$\begin{array}{l}\text { Total economic gain IE } \\
1.0 / 0.55\end{array}$} & \multirow{2}{*}{$\begin{array}{l}\text { Sum } 3 \% \text { DALYs } \\
\text { averted }\end{array}$} & \multirow[b]{2}{*}{ \$/DALY } & \multicolumn{2}{|l|}{ ROI } \\
\hline & & & & & High & Low \\
\hline EF 0.2/0.5 & 4367139093 & 11523037315 & 748964 & 263 & 58 & 22 \\
\hline EF 0.3/0.6 & 5828471895 & 15338406750 & 990300 & 199 & 78 & 30 \\
\hline EF 0.4/0.7 & 7289804696 & 19153776186 & 1231636 & 160 & 97 & 37 \\
\hline EF $0.5 / 0.8$ & 7887383521 & 20705625284 & 1325678 & 149 & 105 & 40 \\
\hline EF 0.6/0.9 & 10212470298 & 26784515057 & 1714308 & 115 & 136 & 52 \\
\hline
\end{tabular}

DALY, disability-adjusted life year; IE, income elasticity; ROI, return on investment. 
the programme. Even at the lowest value modelled, the speculated ROI was still 22, and cost per DALY averted was 263.

The IE estimates are derived from the economic literature, but also are at best estimates given the relative absence of empirical VSL studies from LMICs.

VSL can be criticised as overly hypothetical, and its determination difficult. It also is subject to cultural, economic, national, regional and possibly even religious differences. By calculating a country-specific VSL for each country represented in this study, we attempted to account for at least the national economic differences. How cultural or religious perspectives might play into how people view the value of their lives is more difficult to evaluate. We used the IE as a way to allow for how these perspectives might affect VSL.

VSL was conceived as a tool to evaluate life, with its value to be used as a whole. It was not conceived to be used with its value split into fractions of the whole in order to evaluate disability or impairment. This issue is consistent with the model of DALYs (or healthy-adjusted life years, quality-adjusted life years or other measurements of health) as opposed to using only mortality as a health measure. This extrapolation has not been subjected to the type of sociological studies conducted by Viscusi and colleagues that established the value of VSL. By applying the age weighting data in our calculation of VSLY, however, we have attempted to make this conversion valid in this study.

Ideally, the economic impact of a surgical intervention would be evaluated by a long-term field study examining the economic difference over a lifetime between individuals who had benefited from surgical care and those who had not. This option is, however, not logistically, financially or ethically feasible-hence, modelling techniques remain the mainstay.

\section{CONCLUSIONS}

This study applies a widely used economic approach to attempt to capture the societal gain provided by a large surgical intervention programme in developing countries. It demonstrates the use of VLW modelling, as applied in the LCoGS to overall surgical activity in the world, to a specific surgical problem. As opposed to extending the meaning of per capita economic output measures such as GNI per capita beyond its original intent, this methodology attempts to capture the total economic welfare gains, which include the value of good health in and of itself, associated with surgical repair of CLP. Pursuant to the overarching economic estimates of surgical care described in the LCoGS, it refines the application of VLW methodology to a single surgical intervention. Given the large economic value shown by this study in a scaled vertical surgical programme, it suggests that there is a strong economic argument for greater emphasis on the expansion of surgical care for the majority of the global population that is currently underserved.

\section{Author affiliations}

${ }^{1}$ Murfreesboro, Tennessee, USA

${ }^{2}$ Office of Global Surgery, Massachusetts Eye and Ear Infirmary, Boston, Massachusetts, USA

${ }^{3}$ Program in Global Surgery and Social Change, Department of Global Health Equity, Harvard Medical School, Boston, Massachusetts, USA

${ }^{4}$ Department of Otology and Laryngology, Harvard Medical School, Boston, Massachusetts, USA

${ }^{5}$ MyungSung Christian Medical Center, Addis Ababa, Oromia, Ethiopia

${ }^{6}$ Montreal Children's Hospital, Montreal, Quebec, Canada

${ }^{7}$ Department of Plastic and Reconstructive Surgery, Boston's Children

Hospital, Boston, Massachusetts, USA

${ }^{8}$ Program in Global Surgery and Social Change, Harvard Medical School, Boston, Massachusetts, USA

${ }^{9}$ Office of Global Surgery, Massachusetts Eye and Ear Infirmary, Boston, Massachusetts, USA

\section{Handling editor Seye Abimbola.}

Twitter Follow Daniel Corlew @ScottCorlew and John Meara @JohnMeara

Acknowledgements The authors express their appreciation to MacKinnon Engen of The Smile Train for making the database available for the analysis.

Contributors DSC originally conceived the study, coordinated the collaboration, did the mathematical data analysis, wrote the initial outline of the manuscript and managed the review process and completion. BCA was instrumental in the design of the study and the concept of using the value of lost welfare (VLW) and value of a statistical life (VSL) economic analysis, provided the expertise for that methodology with MGS, worked with the mathematical data analysis, worked extensively on the manuscript, wrote most of the Methods section, and performed a final review of the manuscript. DP originally conceived the study with DSC, worked extensively on the manuscript with multiple revisions, was instrumental in bringing the project to fruition and performed a final review of the manuscript. JGM assembled the collaborators, was instrumental in the concept of the economic analysis used, worked extensively on multiple revisions of the manuscript and performed a final review of the manuscript. MGS was instrumental in the design of the study and the use of VLW and VSL methodology, worked extensively on the manuscript with multiple revisions, helped provide clarity to its role in the literature, and performed a final review of the manuscript.

Funding The Smile Train funded the publication fee only.

Competing interests None declared.

Provenance and peer review Not commissioned; externally peer reviewed.

Data sharing statement No additional data are available.

Open Access This is an Open Access article distributed in accordance with the Creative Commons Attribution Non Commercial (CC BY-NC 4.0) license, which permits others to distribute, remix, adapt, build upon this work noncommercially, and license their derivative works on different terms, provided the original work is properly cited and the use is non-commercial. See: http:// creativecommons.org/licenses/by-nc/4.0/

\section{REFERENCES}

1. Meara JG, Leather AJM, Hagander L, et al. Global surgery 2030: evidence and solutions for achieving health, welfare, and economic development. Lancet 2015;386:569-624.

2. The Lancet Commission on Global Surgery, Lancet 2015;385: S1-57.

3. Rose J, Weiser TG, Hider P, et al. Estimated need for surgery worldwide based on prevalence of diseases: a modelling strategy for the WHO Global Health Estimate. Lancet Glob Health 2015;3(Suppl 2):S13-20.

4. Shrime MG, Bickler SW, Alkire BC, et al. Global burden of surgical disease: an estimation from the provider perspective. Lancet Glob Health 2015;3(Suppl 2):S8-9.

5. Warf BC, Alkire BC, Bhai S, et al. Costs and benefits of neurosurgical intervention for infant hydrocephalus in sub-Saharan Africa. J Neurosurg Pediatr 2011;8:509-21. 
6. Alkire B, Hughes CD, Nash K, et al. Potential economic benefit of cleft lip and palate repair in sub-Saharan Africa. World J Surg 2011;35:1194-201.

7. Alkire BC, Vincent JR, Burns CT, et al. Obstructed labor and caesarean delivery: the cost and benefit of surgical intervention. PLOS ONE 2012;7:e34595.

8. Corlew DS. Estimation of impact of surgical disease through economic modeling of cleft lip and palate care. World $J$ Surg 2010;34:391-6.

9. Gosselin RA, Maldonado A, Elder G. Comparative cost-effectiveness analysis of two MSF surgical trauma centers. World J Surg 2010;34:415.

10. Alkire BC, Shrime MG, Dare AJ, et al. Global economic consequences of selected surgical diseases: a modelling study. Lancet Glob Health 2015;3(Suppl 2):S21-7.

11. Alkire BC, Raykar NP, Shrime MG, et al. Global access to surgical care: a modelling study. Lancet Glob Health 2015;3:e316-323.

12. Shrime MG, Dare AJ, Alkire BC, et al. Catastrophic expenditure to pay for surgery worldwide: a modelling study. Lancet Glob Health 2015;3(Suppl 2):S38-44.

13. Evans D, Tan-Torres Edejer T, Chisholm D, et al. WHO guide to identifying the economic consequences of disease and injury. Geneva: World Health Organization, 2009.

14. Corlew DS. Economic modeling of surgical disease: a measure of public health interventions. World J Surg 2013;37:1478-85.

15. Ashenfelter $O$. Measuring the value of a statistical life: problems and prospects. Econ J 2006;116:C10-23.

16. Poenaru D. Getting the job done: analysis of the impact and effectiveness of the Smile Train Program in alleviating the global burden of Cleft Disease. World J Surg 2013;37:1562-70.

17. Poenaru D, Lin D, Corlew DS. Economic valuation of the global burden of cleft disease averted by a large cleft charity. World J Surg 2016;40:1053-9.

18. United Nations Population Division. World population prospects2015 revision. New York, 2015.

19. The World Bank: open data (world development indicators). 2014 http://data.worldbank.org/ (accessed 15 Oct 2014).

20. Lopez A. Global Burden of Disease and Risk Factors. In: Lopez AD, Mathers CD, Ezzati M, Jamison DT, Murray CJL, eds. Library. New York, NY: Oxford University Press \& The World Bank, 2006: Table 3.A.6, 123.

21. McCord C, Chowdhury Q. A cost effective small hospital in Bangladesh: what it can mean for emergency obstetric care. Int J Gynaecol Obstet 2003;81:83-92.
22. Shillcutt SD, Clarke MG, Kingsnorth AN. Cost-effectiveness of groin hernia surgery in the Western Region of Ghana. Arch Surg 2010;145:954-61.

23. Gosselin RA, Thind A, Bellardinelli A. Cost/DALY averted in a small hospital in Sierra Leone: what is the relative contribution of different services? World J Surg 2006;30:505-11.

24. Wu VK, Poenaru D. Burden of surgically correctable disabilities among children in the Dadaab Refugee Camp. World J Surg 2013;37:1536-43.

25. Viscusi WK, Aldy JE. The value of a statistical life: a critical review of market estimates throughout the world. J Risk Uncertain 2003;27:5-76.

26. Hammitt JK, Robinson LA. The income elasticity of the value per statistical life: transferring estimates between high and low income populations. J Benefit Cost Anal 2011;2:Article 1.

27. Hughes CD, Babigian A, McCormack S, et al. The clinical and economic impact of a sustained program in global plastic surgery: valuing cleft care in resource-poor settings. Plast Reconstr Surg 2012;130:87e-94e.

28. Abegunde D, Stanicole A. An estimation of the economic impact of chronic noncommunicable diseases in selected countries. Geneva: World Health Organization, 2006.

29. Abegunde DO, Mathers CD, Adam T, et al. The burden and costs of chronic diseases in low-income and middle-income countries. Lancet 2007;370:1929-38.

30. Wilson J, Hodges A. Cleft lip and palate surgery carried out by one team in Uganda: where have all the palates gone? Cleft Palate Craniofac J 2012;49:299-304.

31. Christensen K, Juel K, Herskind AM, et al. Long term follow up study of survival associated with cleft lip and palate at birth. $B M J$ 2004;328:1405-6.

32. Carlson L, Hatcher KW, Vander Burg R. Elevated infant mortality rates among oral cleft and isolated oral cleft cases: a meta-analysis of studies from 1943 to 2010 . Cleft Palate Craniofac $J$ 2013;50:2-12.

33. Dai L, Zhu J, Mao M, et al. Time trends in oral clefts in Chinese newborns: data from the Chinese National Birth Defects Monitoring Network. Birth Defects Res Part A Clin Mol Teratol 2010;88:41-7. cited in Carlson.

34. WHO. Global burden of disease 2004 update: disability weights for diseases and conditions. http://www.who.int/healthinfo/global burden disease/GBD2004 DisabilityWeights.pdf (accessed $18 \mathrm{Ju}$ 2012). 